\title{
Performance Characteristics of the UniCel DxI 800 Immunoassay for the Maternal Serum Quadruple Test, Including Median Values for Each Week of Gestation, in Korean Women
}

\author{
Jeong Hoon Lee, M.D. ${ }^{1}$, Yongjung Park, M.D. ${ }^{1}$, Borum Suh, M.D. ${ }^{1}$, Seon-Mi Song, M.D. ${ }^{2}$, Oh Hun Kwon, M.D. ${ }^{1}$, \\ and Jeong-Ho Kim, M.D. ${ }^{1}$ \\ Department of Laboratory Medicine', Yonsei University College of Medicine, Seoul; Division of Immunology², Department of Laboratory \\ Medicine, Seoul Medical Science Institute, Seoul Clinical Laboratories, Seoul, Korea
}

\begin{abstract}
Background : Maternal serum prenatal quadruple screening includes testing for alpha-fetoprotein (AFP), human chorionic gonadotrophin (hCG), unconjugated estriol (uE3), and dimeric inhibin A (DIA). We evaluated quadruple screening using an automated platform and looked for any ethnic differences in the median values of each marker.

Methods : We measured the concentrations of each quadruple test analyte using the UniCel Dxl 800 system (Beckman Coulter, USA) in 788 Korean mid-trimester maternal serum samples and calculated their median values using Benetech software (Benetech, Canada). We also compared the results with those obtained using the Immulite 2000 assay (Siemens Healthcare Diagnostics, USA) or ELISA (DSL, USA) in 442 samples.

Results : We obtained mid-trimester median values for each marker. The following are the comparative results for each test using the Immulite 2000 assay or ELISA ( $x$ ) and the UniCel DxI 800 immunoassay (y): AFP, $y=1.10 x+0.01, r=0.925$; $u E 3, y=0.28 x+0.24, r=0.885$; $h C G, y=1.22 x-3047.8$, $r=0.944$; and DIA, $y=0.86 x+15.31, r=0.833$. Assay results for each of the four markers showed good correlations. However, significant biases necessitated new median calculations of prenatal risk estimates in all four tests.

Conclusions : We established gestational age-specific second-trimester median values for four markers in Korean samples using the UniCel Dxl 800 immunoassay system. Despite significant bias, there were good correlations between the results obtained using the UniCel Dxl 800 immunoassay and those obtained using the Immulite 2000 assay. (Korean J Lab Med 2010;30:126-32)
\end{abstract}

Key Words : Prenatal screening, Down syndrome, Immunoassay, Quadruple test

\section{INTRODUCTION}

Maternal serum prenatal quadruple screening includes tests for alpha-fetoprotein (AFP), human chorionic gonadotrophin (hCG), unconjugated estriol (uE3), and dimeric

Received: September 15, 2009

Manuscript No : KJLM09-114

Revision received : February 24, 2010

Accepted: March 22, 2010

Corresponding author : Jeong-Ho Kim, M.D.

Department of Laboratory Medicine, Gangnam Severance

Hospital, Yonsei University College of Medicine, 712 Eonju-ro, Gangnam-gu, Seoul 135-720, Korea

Tel : +82-2-2019-3532 Fax : +82-2-2019-4822

E-mail : jeongho@yuhs.ac inhibin A (DIA). Measurements of maternal serum AFP, $\mathrm{uE3}$, and hCG, as well as maternal age, are widely used in the second trimester for the identification of pregnancies at high risk of Down syndrome [1, 2]. The maternal serum mid-trimester triple marker test is also a widely accepted protocol in Korea [3-5]. The triple test (AFP, uE3, hCG) is known to have a $71.3 \%$ sensitivity at a $5 \%$ false-positive rate. However, when the gestational age is established by ultrasound, the quadruple test (AFP, uE3, hCG, DIA) has been demonstrated to have a better sensitivity of $77.5 \%$ at a $5 \%$ false-positive rate [6-8]. Many platforms are com- 
mercially available for triple tests; however, DIA currently has only two platforms - either ELISA (Diagnostic Systems Laboratories, Webster, TX, USA) or the Beckman Coulter UniCel DxI 800 system or Access 2 (Beckman Coulter, Fullerton, CA, USA).

To date, DIA has been assayed using an ELISA method; however, this method is time consuming and requires considerable labor, thereby resulting in a long turnaround time. However, Beckman Coulter has launched a DIA product that is used in conjunction with an automated chemiluminescence analyzer, and Lambert-Messerlian et al. [9] recently published median values for DIA using the Beckman Coulter Access immunoassay system in 570 women of European descent. We established the gestational age-specific second-trimester median values for each marker of the quadruple test in Korean second-trimester pregnant women using the Beckman Coulter UniCel DxI 800 immunoassay system in order to make it applicable for use in the Korean population. In addition, we compared the results of the test for each marker using the UniCel DxI 800 system with those obtained using either the Immulite 2000 assay (Siemens Healthcare Diagnostics, Deerfield, IL, USA) or ELISA.

\section{MATERIALS AND METHODS}

We recruited 788 pregnant Korean women at 15 to 20 weeks gestation who visited the clinics of Yonsei University Health System, or the clinics that refer the quadruple test to Seoul Clinical Laboratories for prenatal checkups. We stored serum samples from each patient in a deep freezer at $-70^{\circ} \mathrm{C}$ after completion of the requested quadruple marker tests using the Immulite 2000 assay or ELISA, and subsequently used these samples for the measurement of beta-hCG, AFP, uE3, and DIA using the UniCel DxI 800 system.

Test imprecision was evaluated by following NCCLS EP 5-A guidelines and using commercially available quality control materials (Lyphocheck Maternal Serum Control Levels 1, 2, and 3, Bio-Rad, Irvine, CA, USA) for 5 days.

The median values for each of the four markers were calculated using Benetech PRA (Benetech Clinical Software
Solutions, Toronto, Canada), using serum samples from women with singleton pregnancies. The quadruple marker serum screening was conducted at Gangnam Severance Hospital (formerly Yongdong Severance Hospital, renamed in March 2009), Yonsei University (Seoul, Korea), and Seoul Clinical Laboratories, an independent medical laboratory. We used the completed week for gestational age estimation. Exclusion criteria for the subjects were as follows: 1) age less than $18 \mathrm{yr}, 2)$ those achieving pregnancy by assisted reproductive technologies, 3) gestational age estimated only by non-ultrasound methods (e.g., LMP), and 4) ethnic origin other than Korean. This study was approved by the institutional review board of the Gangnam Severance Hospital, where a triple marker test was initiated in 1995 and a quadruple marker test has been available since 2007. The clinical laboratory of Gangnam Severance hospital covers three hospitals (Severance Hospital, Gangnam Severance Hospital, and Yongin Severance Hospital) of the Yonsei University Health System.

Quadruple tests (AFP, uE3, hCG, DIA) were conducted using the UniCel DxI 800 system (Beckman Coulter), and the AFP, uE3, and hCG values were compared with the values determined using the Immulite 2000 assay. In addition, DIA results were compared with those obtained by ELISA using 442 stored samples.

Passing-Bablok linear regressions, Spearman correlations,

Table 1. Precision of the Beckman Coulter Dxl for the quadruple assay

\begin{tabular}{llrcc}
\hline \multirow{2}{*}{ Sample } & \multirow{2}{*}{ Level } & Mean & \multicolumn{2}{c}{ CV (\%) } \\
\cline { 4 - 5 } & & & Within-run & Total \\
\hline AFP $(\mathrm{ng} / \mathrm{mL})$ & Low & 9.94 & 3.36 & 4.45 \\
& Middle & 30.14 & 4.25 & 4.14 \\
& High & 76.21 & 3.84 & 3.84 \\
uE3 $(\mathrm{ng} / \mathrm{mL})$ & Low & 0.46 & 5.85 & 5.77 \\
& Middle & 1.45 & 3.02 & 2.79 \\
Beta-hCG $(\mathrm{IU} / \mathrm{mL})$ & High & 4.61 & 4.05 & 4.50 \\
& Low & 7,955 & 2.30 & 2.12 \\
& Middle & 24,300 & 5.39 & 5.07 \\
DIA $(\mathrm{pg} / \mathrm{mL})$ & High & 51,426 & 3.73 & 4.81 \\
& Low & 150.4 & 3.91 & 3.88 \\
& Middle & 390.4 & 5.23 & 5.83 \\
& High & 802.9 & 5.27 & 5.36 \\
\hline
\end{tabular}

Abbreviations: AFP, alpha-fetoprotein; uE3, unconjugated estriol; hCG, human chorionic gonadotrophin; DIA, dimeric inhibin A. 
and Bland-Altman plots were generated using Analyse-It software version 1.71 (Leeds, UK).

\section{RESULTS}

Total coefficients of variation (CV) were estimated according to CLSI Guideline EP5-A2 [10] and the results ranged from $2.1 \%$ to $5.8 \%$ for low, from $2.8 \%$ to $5.8 \%$ for middle, and from $3.8 \%$ to $5.4 \%$ for high variation (Table 1 ).
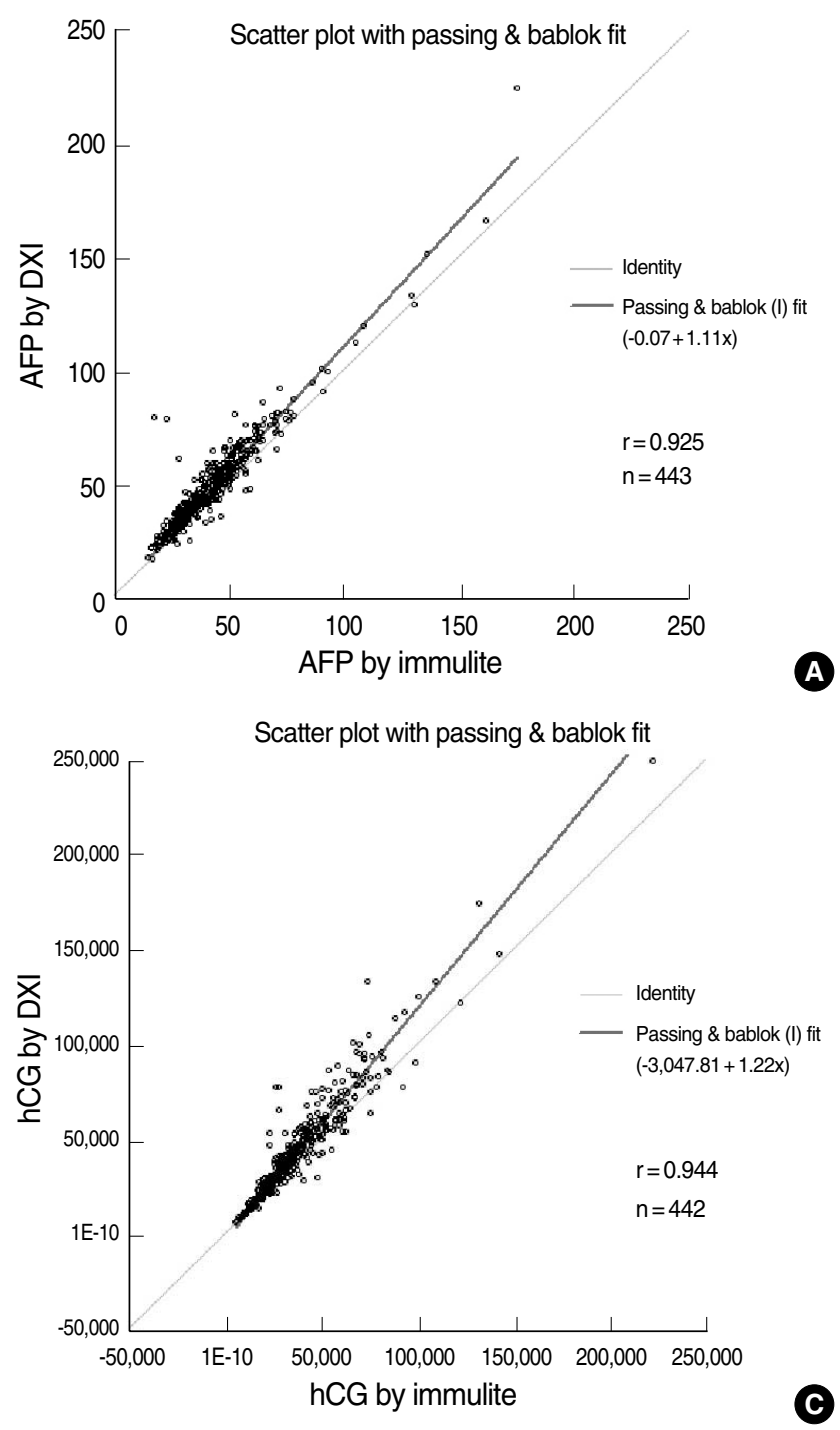

Method comparisons were performed using Passing-Bablok regression and Bland-Altman plots. Passing-Bablok regression produced variable slopes ranging from 0.28 to 1.22 , and Spearman correlation coefficients ranged from 0.833 to 0.944 (Fig. 1). The Bland-Altman plot demonstrates with average bias for each test with the 95\% confidence interval in parentheses were as follows: AFP, 10.7\% (-13.7\% to $35.2 \%)$; uE3, $-91.1 \%$ ( $-125.1 \%$ to $-57.0 \%)$; hCG, $10.8 \%$ (-19.6\% to $41.2 \%)$; DIA, $-8.0 \%$ ( $-53.7 \%$ to $37.8 \%$ ) (Fig. 2).
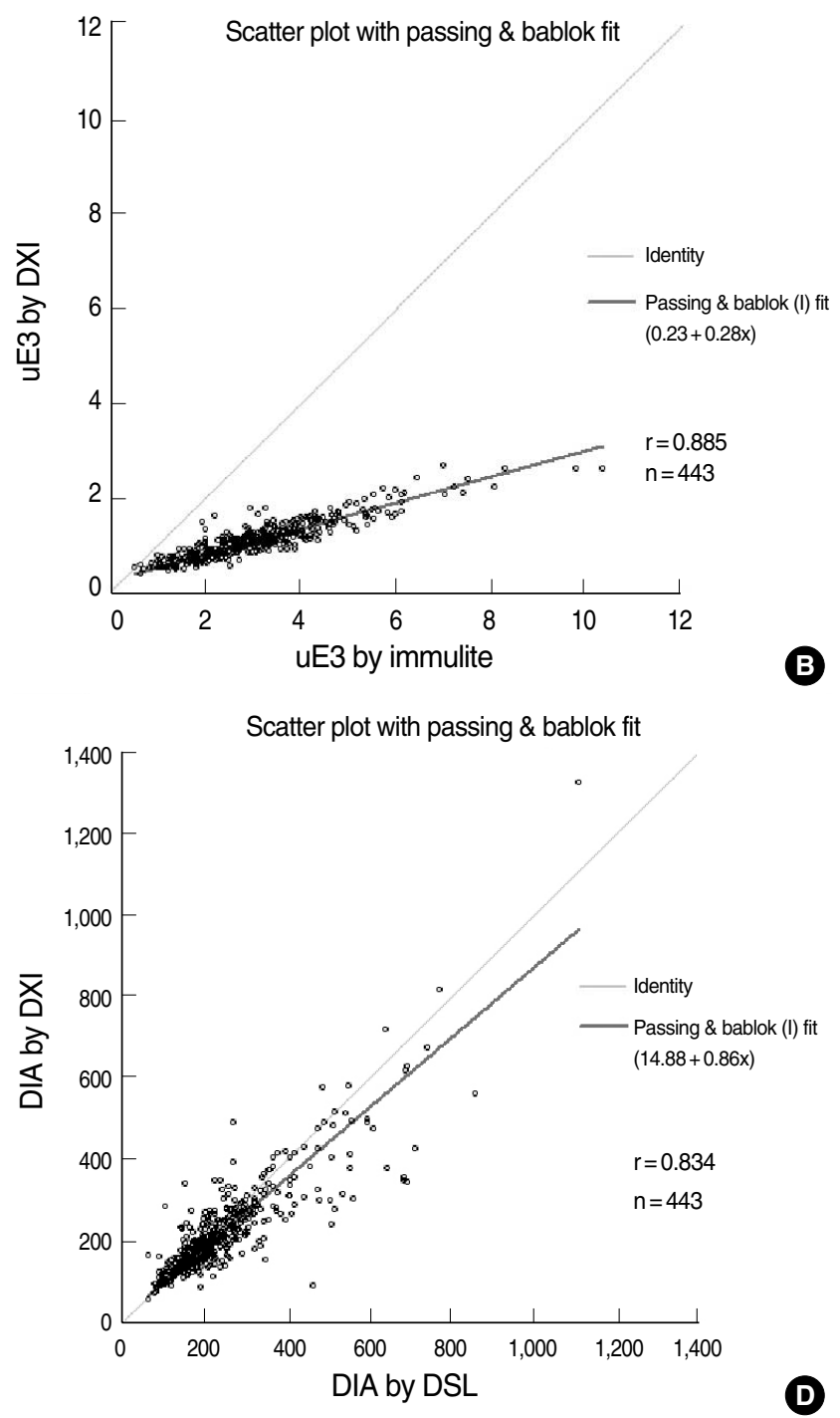

Fig. 1. Comparison study of each of the four tests of the quadruple marker by Dxl vs Immulite or DSL ELISA. (A) AFP, (B) uE3, (C) hCG, (D) DIA.

Abbreviations: DXI, UniCel DxI 800 (Beckman Coulter, Fullerton, CA, USA); Immulite, Immulite 2000 (Siemens Healthcare Diagnostics, Deerfield, IL, USA); DSL ELISA (DSL, Webster, TX, USA); AFP, alpha-fetoprotein; uE3, unconjugated estriol; hCG, human chorionic gonadotrophin; DIA, dimeric inhibin A (DIA). 

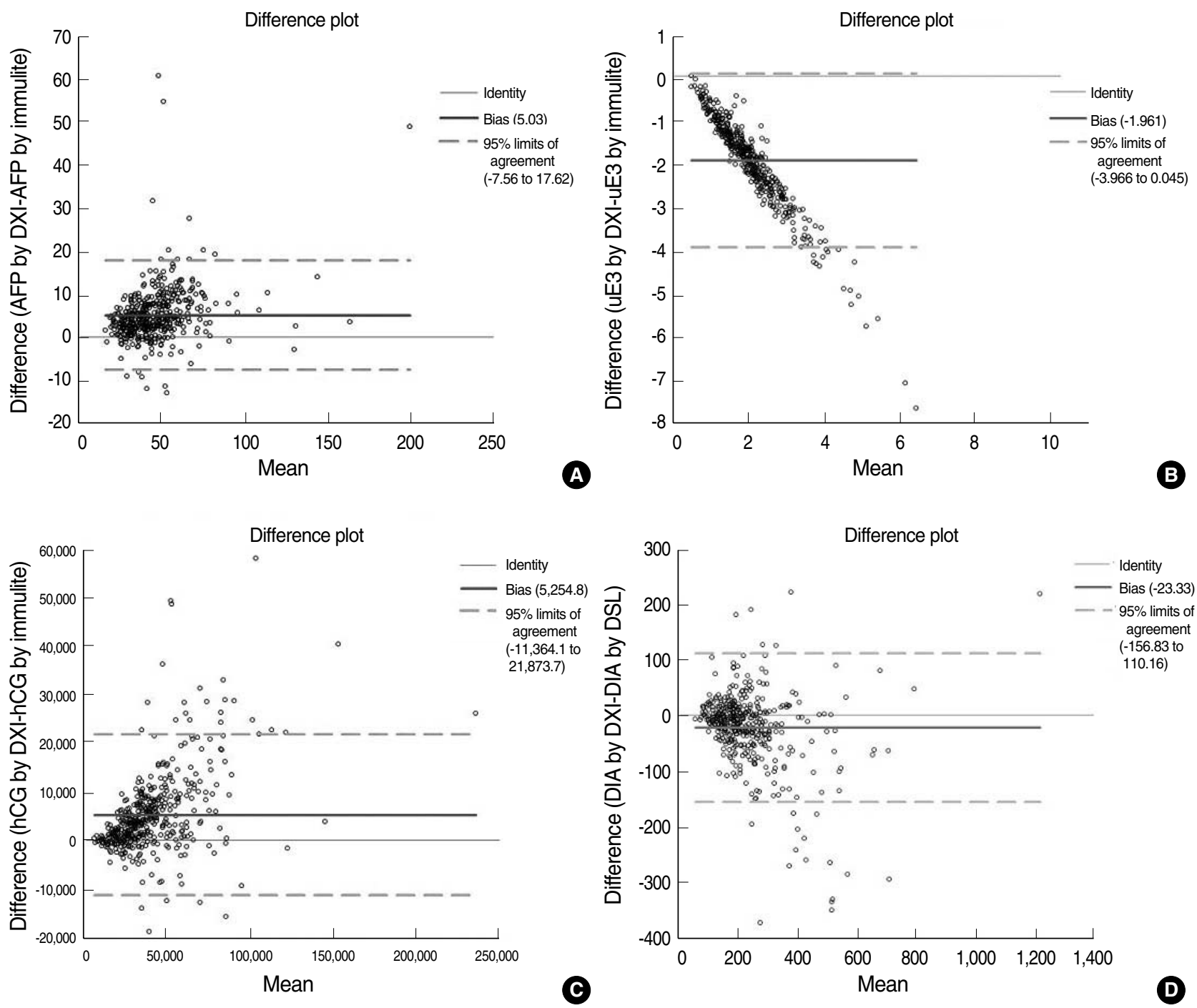

Fig. 2. Bland-Altman plots for each of the four markers in the quadruple test using Unicel DxI 800 vs Immulite 2000 or DSL ELISA. (A) AFP, (B) UE3, (C) hCG, (D) DIA.

Abbreviations: See Fig. 1.

The median values for each of the four markers at 15-20 weeks of gestations are presented in Table 2.

\section{DISCUSSION}

All quadruple test assays conducted using the UniCel DxI 800 immunoassay system yielded results comparable with those obtained using the Immulite 2000 assay or ELISA, but with significant bias, thus necessitating the calculation of median values for prenatal risk estimation. The number of 19th week subjects was slightly less than the recommended number of 100 and there were only 17 subjects in the 20th week. However, the number of subjects in the 15th to the 18th gestational weeks was sufficient for regression analysis of the results for each marker. The median values of DIA in these Korean samples appeared to be higher than those in Western samples [9] (Table 3).

Rawlins et al. [11] reported that DIA Access and ELISA Passing-Bablok analysis yielded a slope of 0.88 (95\% confidence interval [CI], 0.85 to 0.91), an intercept of -3.67 (95\% CI, -16.26 to 6.09), an r value of 0.980, and a BlandAltman analysis mean percentage difference of $-14.6 \%$. We 
Table 2. Median values of each of the four quadruple markers determined using the Beckman Coulter Dxl

\begin{tabular}{|c|c|c|c|c|c|c|c|c|c|}
\hline \multirow{2}{*}{$\begin{array}{l}\text { Gestationa } \\
\text { week* }^{*}\end{array}$} & \multirow{2}{*}{$\begin{array}{c}\text { N. of } \\
\text { samples }\end{array}$} & \multicolumn{2}{|c|}{$\operatorname{AFP}(\mathrm{ng} / \mathrm{mL})$} & \multicolumn{2}{|c|}{ uE3 (ng/mL) } & \multicolumn{2}{|c|}{ hCG (IU/mL) } & \multicolumn{2}{|c|}{ DIA (pg/mL) } \\
\hline & & Obs & $\operatorname{Reg}^{\dagger}$ & Obs & Reg & Obs & Reg & Obs & Reg \\
\hline 15th & 130 & 40.9 & 39.7 & 0.8 & 0.9 & 46.2 & 46.7 & 222.4 & 222.3 \\
\hline 16th & 219 & 44.1 & 45.4 & 1.1 & 1.1 & 37.4 & 36.3 & 188.0 & 190.0 \\
\hline 17th & 160 & 53.4 & 52.0 & 1.4 & 1.4 & 28.7 & 30.2 & 185.3 & 178.1 \\
\hline 18th & 165 & 58.8 & 59.6 & 1.7 & 1.7 & 25.9 & 26.6 & 176.8 & 183.0 \\
\hline 19th & 97 & 67.0 & 68.2 & 2.0 & 2.1 & 26.6 & 24.6 & 209.2 & 206.3 \\
\hline 20th & 17 & 89.1 & 78.1 & 2.8 & 2.7 & 21.1 & 23.4 & 258.9 & 254.9 \\
\hline Total & 788 & & & & & & & & \\
\hline
\end{tabular}

${ }^{*}$ Completed gestational week as determined by ultrasound; 'Regression equations used were derived using Benetech software as follows: Median

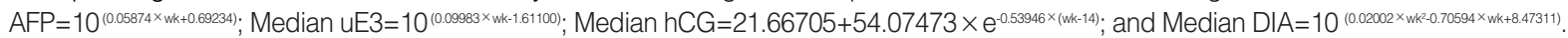

Abbreviations: AFP, alpha-fetoprotein; uE3, unconjugated estriol; hCG, human chorionic gonadotrophin; DIA, dimeric inhibin A; Obs, observed median values; Reg, regressed median values.

Table 3. Comparison of the median values $(\mathrm{pg} / \mathrm{mL})$ of dimeric inhibin A

\begin{tabular}{|c|c|c|c|c|c|c|c|c|c|}
\hline \multirow{2}{*}{$\begin{array}{l}\text { Gestational } \\
\text { week }^{*}\end{array}$} & \multicolumn{3}{|c|}{ Lambert-Messerlian et al. ${ }^{\dagger}[9]$} & \multicolumn{2}{|c|}{ Rawlins et al. ${ }^{\dagger}[11]$} & \multicolumn{4}{|c|}{ Present study } \\
\hline & $\mathrm{N}$ & Observed & Regressed & $\mathrm{N}$ & Observed & $\mathrm{N}$ & Observed & Regressed $^{\ddagger}$ & $\begin{array}{l}\text { Maternal weight- } \\
\text { corrected values }\end{array}$ \\
\hline 15th & 82 & 157.3 & 147.0 & 2,422 & 166 & 130 & 222.4 & 222.3 & 225.9 \\
\hline 16th & 126 & 126.0 & 138.6 & 3,897 & 149 & 219 & 188.0 & 190.0 & 195.4 \\
\hline 17th & 106 & 134.3 & 135.0 & 2,851 & 150 & 160 & 185.3 & 178.1 & 187.2 \\
\hline 18th & 103 & 142.1 & 136.5 & 1,079 & 151 & 165 & 176.8 & 183.0 & 178.8 \\
\hline 19th & 90 & 147.4 & 143.0 & 526 & 161 & 97 & 209.2 & 206.3 & 206.2 \\
\hline 20th & 58 & 144.4 & 155.4 & 279 & 174 & 17 & 258.9 & 254.9 & 277.7 \\
\hline Total & 565 & & & 11,054 & & 788 & & & \\
\hline
\end{tabular}

${ }^{*}$ Completed gestational week as determined by ultrasound; 'Beckman Coulter Access; ' $L o g$-linear regression; ${ }^{8}$ Median MoM=10 to the power (slope ${ }^{*}$ weight+intercept), slope $=-0.00175$, intercept $=0.22616$.

Table 4. Comparison of dimeric inhibin A (DIA) between automated assay and ELISA

\begin{tabular}{|c|c|c|c|c|c|c|}
\hline Study & $\mathrm{N}$ & Slope & Intercept & r & $\begin{array}{l}\text { Mean } \\
\% \text { dif- } \\
\text { ference }\end{array}$ & $\begin{array}{c}\text { Mean ratio } \\
\text { of the two } \\
\text { assays }\end{array}$ \\
\hline $\begin{array}{l}\text { Lambert-Messer- } \\
\text { lian et al.* }[9]\end{array}$ & 565 & 1.00 & -0.776 & 0.960 & $\mathrm{NE}$ & 0.768 \\
\hline Rawlins et al. ${ }^{*}[11]$ & 119 & 0.88 & -3.67 & 0.980 & $-14.6 \%$ & NE \\
\hline Present study & 447 & 0.86 & 14.88 & 0.834 & $-8.0 \%$ & 0.949 \\
\hline
\end{tabular}

${ }^{\star}$ Beckman Coulter Access.

Abbreviation: NE, not evaluated.

confirmed similar biases and correlations. Lambert-Messerlian et al. [9] reported a slope of 1.001 (95\% CI, 0.998 to 1.004 ) and an intercept of -0.776 (95\% CI, -3.112 to 1.560 ) (Table 4). The UniCel DxI 800 system incorporates an analyzer that is essentially the same as that used in the Access 2 system manufactured by the same company, except that the former is like the integration of four units of the lat- ter. Although we do not know the exact reasons why our results differ slightly from the previous studies $[9,11]$, we suspect that a difference in instrument (UniCel DxI 800 instead of Access) or random error, particularly in ELISA, could be the reasons for the difference. Beckman Coulter claim that there have been no calibrator changes in recent years.

DIA precision (within-run CV, 3.9-5.3\%; total CV, 3.9$5.4 \%)$ in our study was similar to that of Rawlins et al. [11] (within-run CV, 3.2-3.6\%; total CV, 4.1-4.2\%) for similar levels (Table 1). The precision seemed to be better than that reported by Erickson et al. [12] (6.4-8.9\%) using the ELISA method.

We compared triple marker data with the data from samples collected in other countries in a study that used the same Beckman Coulter analyzers-Access 2 or UniCel DxI 800 [13] (Table 5-7). The medians of AFP and hCG levels 
Table 5. Regressed median values of alpha-fetoprotein (AFP) compared with those of samples from other countries

\begin{tabular}{|c|c|c|c|c|c|c|c|}
\hline \multirow{3}{*}{$\begin{array}{l}\text { Gestational } \\
\text { week }^{*}\end{array}$} & \multicolumn{7}{|c|}{ AFP (IU/mL) } \\
\hline & \multicolumn{5}{|c|}{ Vranken et al. [13] } & \multicolumn{2}{|c|}{ Present study } \\
\hline & Belgium & Canada & Germany & UK & USA & Korea $^{\dagger}$ & Weight-corrected $^{\ddagger}$ \\
\hline 14th & 22.1 & - & 21.8 & 23.6 & - & - & - \\
\hline 15th & 25.8 & 27.5 & 25.3 & 27.0 & 25.7 & 32.8 & 31.9 \\
\hline 16th & 30.2 & 31.1 & 29.2 & 30.8 & 29.7 & 37.5 & 38.2 \\
\hline 17th & 35.3 & 35.1 & 32.5 & 35.2 & 34.4 & 43.0 & 43.8 \\
\hline 18th & 41.2 & 39.7 & 37.5 & 40.2 & 39.7 & 49.2 & 49.8 \\
\hline 19th & 48.2 & 44.9 & 46.3 & 46.0 & 46.0 & 56.3 & 55.8 \\
\hline 20th & - & 50.6 & - & 52.5 & 53.2 & 64.5 & 78.0 \\
\hline
\end{tabular}

${ }^{*}$ Completed gestational week as determined by ultrasound; ${ }^{\dagger}$ Median values of this study were converted to IU/mL from ng/mL by multiplying by 0.826 for the comparison; " Median values corrected for maternal weight using log-linear regression, Median MoM=10 to the power (slope*weight+intercept), slope $=-0.00236$, intercept $=0.29407$.

Table 6. Regressed median values of uE3 compared with those of samples from other countries

\begin{tabular}{|c|c|c|c|c|c|c|}
\hline \multirow{3}{*}{$\begin{array}{l}\text { Gesta- } \\
\text { tional } \\
\text { week* }^{*}\end{array}$} & \multicolumn{6}{|c|}{ uE3 (nmol/L) } \\
\hline & \multicolumn{4}{|c|}{ Vranken et al. [13] } & \multicolumn{2}{|c|}{ Present study $^{\dagger}$} \\
\hline & Belgium & Canada & Germany & UK & Korea & $\begin{array}{l}\text { Weight- } \\
\text { corrected }^{\ddagger}\end{array}$ \\
\hline 14th & 2.15 & - & 2.22 & 2.26 & - & - \\
\hline 15th & 2.80 & 2.53 & 3.02 & 2.84 & 3.12 & 2.93 \\
\hline 16th & 3.66 & 3.19 & 3.92 & 3.58 & 3.82 & 3.81 \\
\hline 17th & 4.77 & 3.99 & 5.00 & 4.51 & 4.86 & 4.87 \\
\hline 18th & 6.22 & 4.96 & 6.21 & 5.67 & 5.90 & 5.92 \\
\hline 19th & 8.11 & 6.21 & 7.95 & 7.14 & 7.29 & 6.99 \\
\hline 20th & - & 7.77 & - & 8.99 & 9.37 & 10.00 \\
\hline
\end{tabular}

${ }^{*}$ Completed gestational week determined by ultrasound; 'Median values of this study were converted to $\mathrm{nmol} / \mathrm{L}$ from $\mathrm{ng} / \mathrm{mL}$ by multiplying by 3.47 for the comparison; " Median values corrected for maternal weight using log-linear regression, Median MoM=10 to the power (slope* weight+intercept), slope $=-0.00061$, intercept $=0.09007$.

in Koreans appear to be somewhat higher, although the uE3 levels appear to be similar. Crandall et al. [14] noted somewhat higher AFP concentrations in Asian samples. Bogart et al. [15] noted possibly higher hCG concentrations in Asian samples. uE3 concentrations have been reported to be similar in samples of European and African descent, but have not been reported for Asians [16]. Our study showed similar median values for uE3. Benn et al. [17] postulated that the differences observed in the various studies may be attributable to the inconsistent use of maternal weight correction, heterogeneity in the gestational ages of the screened populations, maternal age differences, and regional differences in the subpopulations of women included in each
Table 7. Regressed median values of human chorionic gonadotrophin (hCG) compared with those of samples from other countries

\begin{tabular}{|c|c|c|c|c|c|c|}
\hline \multirow{3}{*}{$\begin{array}{l}\text { Gesta- } \\
\text { tional } \\
\text { week* }^{*}\end{array}$} & \multicolumn{6}{|c|}{ hCG (IU/mL) } \\
\hline & \multicolumn{4}{|c|}{ Vranken et al. [13] } & \multicolumn{2}{|c|}{ Present study } \\
\hline & Belgium & Canada & Germany & UK & Korea & $\begin{array}{l}\text { Weight- } \\
\text { corrected }\end{array}$ \\
\hline 14th & 37.3 & - & 34.9 & 40.0 & - & - \\
\hline 15th & 30.2 & 42.4 & 26.5 & 33.2 & 46.7 & 43.9 \\
\hline 16th & 24.5 & 34.1 & 21.4 & 27.6 & 36.3 & 35.6 \\
\hline 17th & 19.9 & 28.3 & 18.9 & 22.9 & 30.2 & 26.6 \\
\hline 18th & 16.1 & 24.1 & 17.3 & 19.1 & 26.6 & 23.4 \\
\hline 19th & 13.0 & 21.2 & 14.8 & 15.9 & 24.6 & 23.2 \\
\hline 20th & - & 19.1 & - & 13.2 & 23.4 & 19.6 \\
\hline
\end{tabular}

${ }^{*}$ Completed gestational week determined by ultrasound; ${ }^{\dagger}$ Median values corrected for maternal weight using log-linear regression, Median $\mathrm{MoM}=10$ to the power (slope ${ }^{*}$ weight+intercept), slope $=-0.00258$, intercept $=0.29094$.

group.

In addition, Benn et al. [18] and Serdar et al. [19] reported that analytical variations have a great impact on second trimester risk estimation procedures and some articles have reported borderline cases as being problematic [18, 20]. A survey report of external quality control samples for 9 clinical laboratories in Korea showed variable results for the borderline cases that necessitated standardization [21].

An automated platform for quadruple screening has several advantages over manual ELISA, namely, better precision (3.9-5.8\% vs 6.1-7.8\%), faster turnaround time (1 hr vs $5 \mathrm{hr}$ ), and random access function vs batch mode in terms of DIA. 
In conclusion, quadruple test assays conducted using the UniCel DxI 800 system yielded results comparable to those obtained using the Immulite 2000 assay, but with significant bias, thus necessitating the calculation of median values. We established median values for each week of gestation (15 to 20 weeks) for each marker in Korean women.

\section{REFERENCES}

1. Wald NJ, Cuckle HS, Densem JW, Nanchahal K, Royston P, Chard $\mathrm{T}$, et al. Maternal serum screening for Down's syndrome in early pregnancy. BMJ 1988;297:883-7.

2. Egan JF, Kaminsky LM, DeRoche ME, Barsoom MJ, Borgida AF, Benn PA. Antenatal Down syndrome screening in the United States in 2001: a survey of maternal-fetal medicine specialists. Am J Obstet Gynecol 2002;187:1230-4.

3. Kim JM, Sim AS, Lee EH. Amniotic chromosomal analysis in pregnant women identified by triple-marker testing as screen positive. Korean J Lab Med 2006;26:123-30.

4. Kim SK, Bai SW, Chung JE, Jung YN, Park KH, Cho DJ, et al. Triple marker screening for fetal chromosomal abnormalities in Korean women of advanced maternal age. Yonsei Med J 2001;42:199-203.

5. Han SH, An JW, Jeong GY, Yoon HR, Lee A, Yang YH, et al. Clinical and cytogenetic findings on 31,615 mid-trimester amniocenteses. Korean J Lab Med 2008;28:378-85.

6. Benn PA, Kaminsky LM, Ying J, Borgida AF, Egan JF. Combined second-trimester biochemical and ultrasound screening for Down syndrome. Obstet Gynecol 2002;100:1168-76.

7. Benn PA, Fang M, Egan JF, Horne D, Collins R. Incorporation of inhibin-A in second-trimester screening for Down syndrome. Obstet Gynecol 2003;101:451-4.

8. Wald NJ, Rodeck C, Hackshaw AK, Rudnicka A. SURUSS in perspective. Semin Perinatol 2005;29:225-35.

9. Lambert-Messerlian GM, Palomaki GE, Canick JA. Inhibin A measurement using an automated assay platform. Prenat Diagn 2008; 28:399-403.

10. National Committee for Clinical Laboratory Standards. Evaluation of precision performance of quantitative measurement methods: approved guideline. NCCLS document EP5-A2. 2nd ed. Wayne,
PA: NCCLS, 2004.

11. Rawlins ML, La'ulu SL, Erickson JA, Roberts WL. Performance characteristics of the Access Inhibin A assay. Clin Chim Acta 2008;397: $32-5$.

12. Erickson JA, Ashwood ER, Gin CA. Evaluation of a dimeric inhibin-A assay for assessing fetal Down syndrome: establishment, comparison, and monitoring of median concentrations for normal pregnancies. Arch Pathol Lab Med 2004;128:415-20.

13. Vranken G, Reynolds T, Van Nueten J. Medians for second-trimester maternal serum markers: geographical differences and variation caused by median multiples-of-median equations. J Clin Pathol 2006; 59:639-44.

14. Crandall BF, Lebherz TB, Schroth PC, Matsumoto M. Alpha-fetoprotein concentrations in maternal serum: relation to race and body weight. Clin Chem 1983;29:531-3.

15. Bogart MH, Jones OW, Felder RA, Best RG, Bradley L, Butts W, et al. Prospective evaluation of maternal serum human chorionic gonadotropin levels in 3428 pregnancies. Am J Obstet Gynecol 1991;165: 663-7.

16. Simpson JL, Elias S, Morgan CD, Shulman L, Umstot E, Andersen $\mathrm{RN}$. Second trimester maternal serum human chorionic gonadotropin and unconjugated oestriol levels in blacks and whites. Lancet 1990;335:1459-60.

17. Benn PA, Clive JM, Collins R. Medians for second-trimester maternal serum alpha-fetoprotein, human chorionic gonadotropin, and unconjugated estriol; differences between races or ethnic groups. Clin Chem 1997;43:333-7.

18. Benn PA and Collins R. Evaluation of effect of analytical imprecision in maternal serum screening for Down's syndrome. Ann Clin Biochem 2001;38:28-36.

19. Serdar MA, Tutuncu L, Olgun A, Hasimi A, Ozgurtas T, Erbil MK. The effects of analytical factors on second trimester risk estimations. Int J Gynaecol Obstet 2006;93:28-32.

20. Wald NJ, Bestwick JP, Huttly WJ, Morris JK, George LM. Validation plots in antenatal screening for Down's syndrome. J Med Screen 2006;13:166-71.

21. Kim S, Kim YH, Min WK. Prenatal serum marker screening in Korea: survey results. Korean J Lab Med 2007;27:28-33. 